\title{
A EVOLUÇÃO DO PENSAMENTO HUMANO A PARTIR DO BIOCENTRISMO: UMA FORMA DE PRESERVAÇÃO DO DIREITO NATURAL À VIDA
}

\author{
Flávio Henrique Rosa ${ }^{1}$ \\ Lara Maia Silva Gabrich ${ }^{2}$
}

Resumo: $\mathrm{O}$ artigo reflete, racionalmente, a perspectiva humana, em que sempre prevaleceu a relação indivíduo/sociedade. Por séculos, somente se pensava nessas duas dimensões. Mas, com a evolução científica e o processo evolutivo, foi imposta à humanidade uma existência para além destas dimensões: a confirmação de um equilíbrio ecológico sabiamente construído, sensível às ações e práticas humanas. Frente à visão escurecida pelo antropocentrismo cultural, vislumbra-se a nova ética mundial para regular a realidade, o biocentrismo. Assim, na visão ambientalista, deve-se ter consideração moral por todos os seres vivos e uma visão filosófica para preservar o meio ambiente, o habitat natural da humanidade.

Palavras-chave: Biocentrismo; Meio Ambiente; Animais; Ética; Antropocentrismo.

\section{THE EVOLUTION OF HUMAN THOUGHT FROM THE BIOCENTRISM: A WAY OF PRESERVING THE NATURAL RIGHT TO LIFE}

\begin{abstract}
The article rationally reflects the human perspective, in which the individual / society relationship always prevailed. For centuries, only these two dimensions were thought of. But with scientific evolution and the evolutionary process, an existence beyond these dimensions has been imposed upon humanity: the confirmation of an ecological balance wisely constructed, sensitive to human actions and practices. In the face of the vision darkened by cultural anthropocentrism, one sees the new world ethic to regulate reality, biocentrism. Thus, in the environmentalist view, one must have moral consideration for all living beings and a philosophical view to preserve the environment, the natural habitat of mankind.
\end{abstract}

Keywords: Biocentrism; Environment; Animals; Ethic; Anthropocentrism.

\footnotetext{
${ }^{1}$ Mestrando em Direito Ambiental e Desenvolvimento Sustentável pela Escola Superior Dom Helder Câmara, pesquisador integrante do Grupo de Pesquisa Direito dos Animais, Economia, Cultura, Sustentabilidade e Desafios da Proteção Internacional. Endereço Postal Liégia, nº 48, Bairro Vila Nova Vista, Sabará/MG, CEP: 34710-630. E-mail: henrizbh@gmail.com.

${ }^{2}$ Mestranda em Direito Ambiental e Desenvolvimento Sustentável pela Escola Superior Dom Helder Câmara. Professora das Faculdades Integradas Pitágoras. Pesquisadora integrante do grupo A Mineração e o Desenvolvimento Sustentável nos Tribunais. Endereço postal: Rua Domiciano Pimenta, nº 429, Bairro Jardim São Luiz, Montes Claros/MG, CEP: 39401-051. E-mail: laragabrich@gmail.com.
} 


\section{INTRODUÇÃO}

Desde os tempos mais remotos reconhece-se o utilitarismo sobre os seres sencientes, demonstrando, dessa forma, que a humanidade vivencia a ausência solidária e fraterna entre as espécies de todo planeta. Por sua vez, não somente os animais não humanos são vítimas das agressões, mas, também a própria natureza sofre com a devastação em nome do desenvolvimento e crescimento econômico no antropocentrismo extremo.

Deve-se, portanto, dedicar-se atenção especial ao assunto, pois nunca houve na história do planeta, tal como no século XXI, vigilâncias, tanto para a alarmante questão ambiental, quanto para a vulnerabilidade dos animais em relação às vontades humanas. Nesse diapasão, independentemente de qualquer interesse, seja de cunho individual ou coletivo, deve-se reconhecer que os animais não humanos merecem respeito pelos valores que lhes são inerentes e não pelo que podem oferecer ao bem-estar social coletivo.

A preservação desse habitat é mais do que um problema de desequilíbrio ambiental. É, antes de tudo, um conflito ético condescendente, pois há de se levar em consideração a proteção ao meio ambiente e o bem estar às presentes e às futuras gerações. Contudo, é necessário que no âmbito político haja uma distribuição igualitária de direitos, alçando-se a verdadeira justiça, zelando para que a humanidade não seja indiferente às necessidades dos animais e aos problemas socioambientais que assolam o planeta.

$\mathrm{O}$ texto que ora se apresenta relaciona o homem à natureza como crítica aos direitos à vida e ao seu bem estar natural tendo em vista o desrespeito à fauna e à flora ambiental. Diante dos problemas, essas ações constituem não apenas ameaça à paz, à segurança e ao bem estar social, mas também aos fatores de desequilíbrio dos ecossistemas. Pode-se afirmar que além de provocar escassez de recursos naturais, vislumbram-se também danos irreparáveis como apagar e negar às gerações vindouras o direito ao meio ambiente sadio e à sua própria extinção como espécie.

Assim, é importante desenvolver o diálogo entre disciplinas e outras formas de saberes relacionados com o ambiente como a Economia, a Cultura e a Sustentabilidade dentro de processo de interdependência e de interdisciplinaridade. Faz-se necessário pensar e rediscutir acerca das condições de vida e de sobrevivência da sociedade em rever o lugar do ser humano no mundo e suas relações com a realidade superando a forma incorreta de interpretar sua ancestralidade (REIS; NAVES, 2018). 
Para tanto, na primeira seção será tratado o meio ambiente como a interação e conjunto de elementos naturais, artificiais e culturais que propiciem o desenvolvimento equilibrado da vida em todas as suas formas. Corresponde-se os fatores físicos, científicos e químicos criados pela humanidade e principalmente os fatores biológicos existentes na natureza, como flora, fauna e seus recursos naturais, ou seja, o ecossistema existente.

Em seguida desenvolver-se-á a Bioética, que surge como resposta à ciência e sua construção na pós-modernidade, indicando os limites e as finalidades da intervenção do homem sobre a vida, identificando os valores da referência racionalmente proponíveis, denunciando os riscos das possíveis aplicações. Pois, nem sempre o que a ciência propõe seria adequado à vida. Idealiza-se, contudo, estrutura ética mais cautelosa nas relações entre as bases científicas e as relações humanas, abarcando também questões ambientais e a natureza em sua forma global.

Na terceira seção, discorrer-se-á sobre o Biocentrismo: uma possível ciência capaz de desconstruir a endogenia humana e sua posição centralizadora. Tem como proposta inserir todas as formas de vida como projeto de sociedade, pois nenhuma espécie é superior ou mais importante que a outra, proporcionando uma racionalidade ambiental, a manutenção das desigualdades, uma sustentabilidade em disputa.

A derradeira seção tratará sobre a responsabilidade e torna inviável a assunção acrítica do paradigma antropocêntrico das éticas tradicionais. O biocentrismo fundamenta o princípio da responsabilidade, que valora a dignidade da vida como tal. Isso é uma exigência moral, não só em razão dos humanos, mas também da biosfera e por seu direito próprio.

A pesquisa visa, assim, valorizar e explicitar as ideologias que foram desconsideradas pela epistemologia hegemônica, de conteúdo teórico-bibliográfico, utilizando-se do método hipotético-dedutivo e da pesquisa exploratória baseada no levantamento bibliográfico.

\section{MEIO AMBIENTE, PERFEIÇÃo E EQUILIBRÍO À DISPOSIÇÃo DA HUMANIDADE}

O meio ambiente conforme Milaré (2014) configura-se a interação e conjunto de elementos naturais, artificiais e culturais que propiciem o desenvolvimento equilibrado da vida em todas as suas formas. Corresponde-se os fatores físicos, científicos e químicos criados pela humanidade e principalmente os fatores biológicos existentes na natureza, como flora, fauna e seus recursos naturais, ou seja, o ecossistema existente.

Rev. de Biodireito e Direito dos Animais | e-ISSN: 2525-9695 | Porto Alegre | v. 4 | n. 2 | p. 80 - 98 | Jul/Dez. 2018 
Nesse sentido, assegurar a continuidade da vida no planeta, fundada na solidariedade humana no tempo e no espaço, tornou-se norma constitutiva fundamental, provocando externalidades restritivas uma vez que as suas ações ultrapassaram os aspectos do mundo e da ética.

Ao longo dos anos, a humanidade vinculada às ideologias de progresso, consumo e tecnologia transformaram o meio ambiente. O paradigma antropocêntrico tornou-se tecnocrático. Diante de uma realidade racional e precisamente técnica, o ser humano passou a ocupar outro lugar, o centro, a esfera que determinara o mundo. Por esta razão, não reconhece mais o valor intrínseco dos outros seres e reduz a natureza a puro espaço e matéria de sua ação. (MURAD; TAVARES, 2016).

Como ser autônomo da realidade o homem promove aspirações próprias e necessidades imediatas. Assim, tudo mais se torna relativo, o que não serve aos interesses imediatos perde-se qualquer importância. Nesta concepção, as fontes de energias, de cunho altamente econômico e controlador, produziram desequilíbrios ecológicos determinando uma alteração significativa no cenário social.

Com o crescimento populacional, a necessidade de energia tornou-se ponto culminante atender à demanda populacional nos direitos básicos e fundamentais no que se refere à saúde, moradia, saneamento básico, mobilidade entre outros exigiram áreas cada vez maiores para a produção de alimentos e técnicas de cultivo que aumentem a produtividade da terra.

Florestas cederam lugar a lavouras e criações, espécies animais e vegetais são domesticadas, muitas extintas e outras, ao perderem seus predadores naturais, multiplicam-se aceleradamente. Produtos químicos não-biodegradáveis ${ }^{3}$, usados para aumentar a produtividade e evitar predadores nas lavouras, matam microrganismos decompositores, insetos e aves, reduzem a fertilidade da terra, poluem os rios e águas subterrâneas e contaminam os alimentos. Dessa forma:

\begin{abstract}
A atividade humana, resultante de sua técnica, tendo assumido novos contornos de produção e acumulação, traz consequências para o meio ambiente que, uma vez negativamente modificado, promove alterações no próprio homem através do impacto no quadro geral de saúde. A degradação ambiental e o modo como o homem se comporta no ambiente por ele modificado implica, em muitos casos, no surgimento de doenças. (NASCIMENTO, 2016, p.36)
\end{abstract}

\footnotetext{
${ }^{3}$ Qualquer material que não se decompõe no meio ambiente e ou leva dezenas ou centenas de anos para se decompor. Garrafas plásticas, ferro, sacolas plásticas, pneus, latas e vidro são exemplos de materiais nãobiodegradáveis. Disponível em: http://www.tsambientali.com.br/o-que-e-produto-biodegradavel-e-qual-suaimportancia-para-o-meio-ambiente/ . Acesso em: 18 Jun.2018.
} 
Contudo, percebe-se cada vez com maior clareza que esse crescimento econômicoindustrial se contrapõe à natureza, a base material da vida humana. Há, na sociedade, um conflito de fundo entre a lógica do desenvolvimento econômico e a lógica que governa a biosfera. (MURAD; TAVARES, 2016).

Para Naves e Reis (2016), o ser humano radicalizou tal processo no século XX utilizando-se das ciências da vida, que ampliaram a intervenção humana no mundo vegetal e animal. A biologia foi sem dúvida a ciência que, no último século, fez mais progressos, o que se deve ao emprego em seu domínio da forma de pensar das ciências da natureza, física, química, cibernética. De integrante do meio ambiente, o ser humano passou a se colocar como parte externa ao meio, a que ele domina e submete. (MURAD; TAVARES, 2016).

A percepção da responsabilidade moral precisa compor a educação para o cuidado preventivo, quando se podem antever ações que conduzam ao desequilíbrio entre os ecossistemas, aos conflitos sociais violentos ou a outras formas de destruição e corrupção. (AQUINO; ZAMBAM, 2017).

\section{NOVOS AFRONTAMENTOS ÉTICOS}

Como resposta à ciência e sua construção na pós-modernidade, a Bioética ${ }^{4}$ surgiu na década de 1970 e teve como proposta estudar os impactos das novas tecnologias sobre a vida humana quando o autor Van Rensselaer Potter ${ }^{5}$ publicou a obra Bioethic: Bridge to the future. Em sua essência, a obra idealiza uma estrutura ética mais cautelosa nas relações entres as bases científicas e as relações humanas, abarcando também questões ambientais e a natureza em sua forma global. Pode-se afirmar que:

O termo Bioética incorporou-se em nossos vocabulários e práticas científicas, sendo obrigatórios "comitês de ética em pesquisa" em instituições de ensino e de pesquisa e

\footnotetext{
${ }^{4}$ Bioética (grego: bios, vida + ethos, relativo à ética) é o estudo transdisciplinar entre Ciências Biológicas, Ciências da Saúde, Filosofia (Ética) e Direito (Biodireito) que investiga as condições necessárias para uma administração responsável da Vida Humana, animal e ambiental. Considera, portanto, questões onde não existem consenso moral como a fertilização in vitro, o aborto, a clonagem, a eutanásia, os transgênicos e as pesquisas com células tronco, bem como a responsabilidade moral de cientistas em suas pesquisas e aplicações na área da saúde. Disponível em: http://biologo.com.br/bio/bioetica/. Acesso em: 15 Jun.2018..

${ }^{5}$ Van Rensselaer Potter (27 de agosto de 1911 - 6 de setembro de 2001) foi um bioquímico americano, e pesquisador na área de oncologia. Sua experiência com pacientes oncológicos o fez propor o surgimento de um novo conceito interdisciplinar, o qual correlaciona ética e ciência, o qual denominou de bioética. Disponível em: http://biologo.com.br/bio/bioetica/. Acesso em: 15 Jun.2018.
} 
em institutos médicos, quando as pesquisas envolverem seres humanos. Sem esquecer, todavia, que, desde o seu nascedouro, abrange também questões de uma ética ecológica, que deve ser capaz de avaliar as relações do homem com o meio ambiente em pressupostos de sustentabilidade (SÁ; NAVES, 2009, p.8).

Portanto dividiu-se em Bioética do cotidiano, que analisa a ética profissional, as relações de pesquisas, os relacionamentos interpessoais, mais precisamente, no dia-a-dia e, ainda sim, diz respeito às interferências tecnológicas sobre a vida de uma sociedade frente aos desafios da modernidade. Por conseguinte, teve-se também a Bioética dos grandes temas que se tornam públicos pelas mídias e jornais como o aborto, a eutanásia, a utilização de célulastronco em pesquisa, os transgênicos, entre outros.

Uma das premissas da Bioética é resgatar a essência do relacionamento social e humanístico. Desta feita, vale destacar que a modernidade implantou uma herança de personalidade e costumes que, com o passar do tempo, tornou-se extremamente negativa. Estas tendências afetaram as relações e interferiram nas decisões e valores da pessoa humana. Conforme Santos (1998, p. 40):

Os fatores que contribuíram para a formação bioética são múltiplos. Indicamos apenas alguns que julgamos, significativos. Referimo-nos a fatores de ordem históricocultural, econômico-social e ético-religioso. A história de um povo poderá condicionar a expressão mais rigorosa ou consensual de sua cultura; sua situação econômico-social dirá algo de suas opções no campo da saúde e de seu acesso à tecnologia avançada. A religião e a ética indicarão os valores que elege o direito as regras que segue. Há também outro fator: a tradição filosófica que molda a mentalidade analítica e crítica da comunidade, da qual a fundamentação bioética se torna uma exigência.

Portanto, a Bioética rompe, expande e interfere nos fatos diante das ciências e na qualificação dos valores. Propõe um novo paradigma na relação entre os sujeitos de direito. Assim sendo, os séculos XX e XXI são influenciados por um conjunto de ideias que identificam as pessoas, a sociedade e que, tomadas ao extremo, tornam-se influências negativas rompendo os valores éticos em sua essência do licito e do não-licito. Vale destacar que a ética, para Sgreccia (2009), tem a função de manter o equilíbrio evolutivo, o equilíbrio da mutação, da adaptação e do ecossistema 6 .

\footnotetext{
${ }^{6}$ Ecossistema significa o sistema onde se vive, o conjunto de características físicas, químicas e biológicas que influenciam a existência de uma espécie animal ou vegetal. É uma unidade natural constituída de parte não viva (água, gases atmosféricos, sais minerais e radiação solar) e de parcela viva (plantas e animais, incluindo os microrganismos) que interagem ou se relacionam entre si, formando um sistema estável. Os ecossistemas são divididos em ecossistemas terrestres e ecossistemas aquáticos. É considerado como o conjunto de todos os organismos (biocenose) que habitam em um determinado espaço vital (ecótopo), com a totalidade de fatores
} 
Por assim dizer, cada uma destas situações interfere na vida das pessoas e no planeta como forma geral. Desse modo, de acordo com Sá e Naves (2009, p.8), a Bioética é, "portanto, a disciplina que estuda os aspectos éticos das práticas dos profissionais de saúde e da Biologia, avaliando suas implicações na sociedade e relações entre os homens e entre esses e outros seres vivos".

O termo Bioética, limites da modernidade, define-se como a ciência que estuda principalmente quais são os aspectos negativos e positivos que a interferência das ciências, da tecnologia provocam na vida do ser humano, seja ela particular, seja ela psicológica, que nem sempre são resolvidos pelos instrumentos tradicionais de proteção à vida.

No conceito de Bioética estão implícitas três funções: a descritiva, a normativa e a protetora. A primeira analisa os problemas estabelecendo a relação destes para os possíveis conflitos, soluções e as atitudes a serem tomadas. A segunda determina quais as ações aceitáveis e a não aceitáveis para o problema impondo limites e deveres aos envolvidos. Já a terceira, amparada ao principio da justiça, estabelece níveis de igualdade entre as partes seja econômico ou científico.

Como Virtude, a Bioética vincula-se à Ética no agir consciente e responsável do agente. Como fundamento, a Bioética concilia o desenvolvimento das ciências tecnológicas às exigências morais da sociedade, novos saberes, outra forma de educação.

Portanto, a Bioética tem como objetivo indicar os limites e as finalidades da intervenção do homem sobre a vida, identificar os valores da referência racionalmente proponíveis, denunciar os riscos das possíveis aplicações. Porque nem sempre o que a ciência vai propor é adequado à vida.

Enfatizando esses aspectos, pode-se afirmar que:

\begin{abstract}
Em outras palavras, mesmo desconsiderando suas obras objetivas, a tecnologia assume um significado ético por causa do lugar central que ela agora ocupa subjetivamente nos fins da vida humana. Sua criação cumulativa, isto é, o meio ambiente artificial em expansão, reforça, por contínuo efeito retroativo, os poderes especiais por ela produzidos: aquilo que já foi feito exige o emprego inventivo incessante daqueles mesmo poderes para manter-se e desenvolver-se, recompensando-o com um sucesso ainda maior - o que contribui para o aumento de suas ambições (JONAS, 2006, p.43).
\end{abstract}

inanimados desse espaço. Vários ecossistemas parecidos formam um bioma. Disponível em: http://www.meioambiente.ufrn.br/?p=21710. Acesso em: 24 jun.2018. 
A projeção da ética de Jonas (2006) para o futuro conduz até mesmo a um "sujeito" que não existe, não reivindica e não tem seus direitos lesados: as futuras gerações. E mais: dirige-se também a outras formas de vida, já que a ética passa a ser uma parte da filosofia da natureza.

Mas, para tornar possível este acontecimento, é necessário atribuir um debate transdisciplinar, composto por diversas áreas do conhecimento, para contribuir e formular questões e soluções a respeito desta interferência das tecnologias sobre a vida para, então, a partir desta, estabelecer uma ponte ligação entre o conhecimento humanístico e o conhecimento tecnológico, novos elementos, nova liquidez, diante da falta de certezas.

Para lidar com isso, o aporte ambiental, a Bioética exerce função sustentável promovendo a reflexão da sociedade humana para o atual modelo de desenvolvimento na expectativa de preservar e cuidar para as futuras gerações. Assim,

\begin{abstract}
[...] o homem atual é cada vez mais o produtor daquilo que ele produziu e o feitor daquilo que ele pode fazer; mais ainda, é o preparador daquilo que ele, em seguida, estará em condição de fazer. Mas quem é "ele"? Nem vocês nem eu: importam aqui o ator coletivo e o ato coletivo, não o ator individual e o ato individual; o horizonte relevante da responsabilidade é fornecido muito mais pelo futuro indeterminado do que pelo espaço contemporâneo da ação. [...] Se a esfera do produzir invadiu o espaço do agir essencial, então a moralidade deve invadir a esfera do produzir, da qual ela se mantinha afastada anteriormente, e deve fazê-lo na forma de política pública. Nunca antes a política pública teve de lidar com questões de tal abrangência e que demandassem projeções temporais tão longas. De fato, a natureza modificada do agir humano altera a natureza fundamental da política (JONAS, 2006, p. 44).
\end{abstract}

Vale a pena destacar que a Bioética é uma proposta além da dogmática jurídica. $\mathrm{Na}$ concepção de Sá e Naves (2009), visa permitir uma ampla investigação, tendo sempre em consideração os valores éticos e os fins da sociedade, principalmente a existência material do ecossistema.

Porém, nos últimos dois séculos, como destacam Reis e Bizawu (2015, p. 47), segundo os quais revela uma das grandes intuições da modernidade de Francis Bacon - "Saber é poder":

o progresso científico legou importantes ganhos para a humanidade. O homem necessitou adaptar-se na natureza a fim de perpetuar sua sobrevivência, por isso, claramente, a técnica não pode ser criticada em si mesmo. mas por outro lado, a técnica moderna está associada ao poder.

Vale dizer que o saber está atrelado ao aspecto econômico, porquanto: 
Nunca a humanidade teve tanto poder sobre si mesma, e nada garante que o utilizará bem, sobretudo se se considera a maneira como o está a fazer. Basta lembrar as bombas atómicas lançadas em pleno século XX, bem como a grande exibição de tecnologia ostentada pelo nazismo, o comunismo e outros regimes totalitários e que serviu para o extermínio de milhões de pessoas, sem esquecer que hoje a guerra dispõe de instrumentos cada vez mais mortíferos. Nas mãos de quem está e pode chegar a estar tanto poder? É tremendamente arriscado que resida numa pequena parte da humanidade (PAPA FRANCISCO, 2015, p. 81).

A maneira como o homem tecnológico posiciona-se ante a natureza é como um sujeito que manipula e apropria-se dos objetos exteriores a ele. Assim, as coisas passam a noção de poderem estar disponíveis infinitamente. Tal paradigma proporciona a impressão de ser definitivo. Para Francisco, então, entende-se que "É preciso reconhecer que os produtos da técnica não são neutros, porque criam uma trama que acaba por condicionar os estilos de vida e orientam as possibilidades sociais na linha dos interesses de determinados grupos de poder" (REIS; BIZAWU, 2015).

Tal paradigma leva à crença de que todos os problemas da humanidade serão resolvidos por meio do crescimento econômico, mas não levam em consideração, necessariamente, a desigualdade social, o cuidado com o meio ambiente e com as gerações futuras, aspecto a considerar a pluralidade de autores, a ausência de projetos de sociedades.

A economia, a ciência e a técnica buscam uma autossuficiência, sem preocuparem-se com o diálogo com outras áreas, e isso leva à crença de que a solução para os problemas criados por elas sejam solucionados sem a necessidade de intervenção de outros campos do saber ou paradigmas de vida: “A ciência e a tecnologia não são neutrais, mas podem, desde o início até ao fim de um processo, envolver diferentes intenções e possibilidades que se podem configurar de várias maneiras" (REIS; BIZAWU, 2015).

\section{A MACROBIOÉTICA: BIOCENTRISMO DIANTE DO ANTROPOCENTRISMO}

É nesse novo contexto que se pode compreender os problemas que emergem na pósmodernidade, ainda mais agravados pela incerteza a respeito dos efeitos das novas tecnologias altamente eficientes. Assim, destaca-se que há consequências econômicas, politicas, sociais e étnicas deste processo em perspectiva global e para as futuras gerações, o que significa dizer que se está transferindo para elas problemas de proporções gigantescas (MURAD; TAVARES, 2016). 
Dentro dessa nova e influente sensibilidade ecológica, mas de forma autônoma, desenvolve-se uma corrente filosófica ética contrária à ética antropocêntrica clássica que foi responsável por uma transformação na postura do homem em relação à natureza. De integrante do meio ambiente, o ser humano passou a colocar-se como parte externa ao meio, a que ele domina e submete (NAVES; REIS, 2016).

Portanto, corresponde à responsabilidade recíproca entre os seres e o cuidado com o meio social em que se vive como dever de todos. Conclui-se que o homem, ao exercer a liberdade, expõe o ser e transforma seus projetos de vida como sua existência, como afirma Sgreccia (2009, p.74):

\begin{abstract}
Quando, aliás, a liberdade se volta contra a vida, destrói a si mesma e seca a sua raiz; quando nega a responsabilidade da escolha, reduz-se a força cega e arrisca o jogo consigo mesma e o suicídio. Ao falar de responsabilidade, falamos certamente da responsabilidade que nasce dentro da liberdade e é sustentada pela razão, que avalia meios e fins para um projeto livremente perseguido; não queremos dar a entender, ao menos aqui, a responsabilidade diante da lei civil e da autoridade externa, que pode ter razão em ser invocada para certos valores de bem comum, mas não é a primeira nem a maior expressão de responsabilidade. Essa, é antes de mais nada, interior diante da razão e de seu reflexo sobre a consciência, sobre a avaliação ética dos valores em jogo; essa responsabilidade permanece, mesmo quando a lei civil se cala e o magistrado não sabe e não indaga; às vezes, essa responsabilidade interior pode até se ver em contraste com a lei civil, quando esta chega a ofender os valores fundamentais e irrenunciáveis da pessoa humana.
\end{abstract}

O Biocentrismo é uma teoria que propõe e declara que todas as formas de vida são importantes, ao contrário do antropocentrismo, ao considerar a humanidade como o centro do universo, e entende que as demais espécies existem para servir os homens. Trata-se de uma perspectiva que conecta a humanidade com todos os seres do planeta, criando a profunda e complexa teia da vida (NAVES; REIS,2016).

Diante disso, fica evidente que não existem divisões entre a humanidade e o ambiente, e um depende do outro para sobreviver e desenvolver-se. Tomando por base esse contexto teórico, é importante frisar que a destruição ambiental causada pela ação humana é prejudicial, não apenas para a natureza, mas para a humanidade e para a vida como um todo, desequilibra toda uma unidade já planejada e atemporal às vontades seculares de uma espécie em si.

Nesse sentido, Murad e Tavares (2016) enfatizam que a concepção de desenvolvimento como crescimento econômico faz parte do paradigma tecnocrático dominante, em que a economia assume todo o desenvolvimento tecnológico em função do lucro, sem prestar atenção nas eventuais consequências negativas para o ser humano. E, ainda, tende a 
gerar automatismos e a homogeneizar, a fim de simplificar os processos e reduzir os custos. Por isso, é necessária uma ecologia econômica, capaz de induzir a considerar a realidade de forma mais ampla. Logo,

\begin{abstract}
As gritantes desigualdades sociais, a instabilidade democrática e a expropriação dos recursos naturais e ambientais estão na origem dos altos índices de pobreza e escassez de recursos indispensáveis para a qualidade de vida. Os alicerces de uma "Casa Comum" não podem ser constituídos pela ignorância, miséria, opressão, submissão e eliminação, mas pelo esclarecimento e pela importância da diversidade vital que habita os ecossistemas neste continente. O cuidado da "Casa Comum" ultrapassa fronteiras territoriais, círculos de interesses corporativos, grupos culturais, instituições e outros, para estabelecer condições e compromissos que visem a uma postura de preservação, admiração e utilização equilibrada dos recursos disponíveis. O seu discurso e práxis são, essencialmente, caracterizados por um fundamento ético e de justiça. Nesse cenário de dificuldades e ameaças, essa abordagem clama para a superação da indiferença e dos objetivos de curto prazo ou restritos aos Estados e a tolerância com ações, individuais ou coletivas, irresponsáveis em relação ao meio ambiente, às culturas e ao equilíbrio social (AQUINO; ZAMBAM, 2017, p. 119).
\end{abstract}

Na perspectiva de Murad e Tavares (2016), caso a ética e as políticas socioambientais fossem inteiramente baseadas nas teorias biocentristas, certamente GAYA tornaria-se muito mais sustentável e preocupada com as questões ambientais, eliminando o consumo desenfreado de recursos naturais e a degradação ambiental, de modo geral, atendendo às necessidades de todas as espécies em sua própria medida vital.

De forma análoga, Leff (2010) argumenta que a resolução dos problemas ambientais, assim como a possibilidade de incorporar condições ecológicas e bases de sustentabilidade aos processos econômicos - de internalizar as externalidades ambientais na racionalidade econômica e os mecanismos do mercado - e para construir uma racionalidade ambiental e um estilo alternativo de desenvolvimento, implica a ativação e objetivação de um conjunto de processos sociais: a incorporação de valores do ambiente na ética individual; a socialização do acesso e apropriação da natureza: a democratização dos processos produtivos e do poder político.

Porém, não há razão para manter esta postura e sim há muitas razões para mudar. O Biocentrismo inclui para a centralidade aqueles que são dotados de sensação e principalmente os seres não dotados como as plantas e o ecossistema. Sendo assim, declinar a ética da discriminação arbitrária daqueles que não pertencem a uma determinada espécie uma vez que os consideram seres inferiores e os colocam num patamar abaixo do seu, não lhes conferindo qualquer tipo de direitos. Diante disso, fica evidente que: 


\begin{abstract}
A construção de uma racionalidade ambiental é um processo político e social que passa pelo confronto e concerto de interesses opostos, pela reorientação de tendências (dinâmica populacional, racionalidade do crescimento econômico, padrões tecnológicos, praticas de consumo); pela ruptura de obstáculos epistemológicos e barreiras institucionais; pela criação de novas formas de organização produtiva, inovação de novos métodos de pesquisa e produção de novos conceitos e conhecimentos (LEFF, 2010, p.112).
\end{abstract}

Nessa linha de raciocínio, Leff (2010) demonstra que a questão ambiental propõe assim a necessidade de um pensamento holístico e sistêmico, capaz de perceber as inter-relações entre os diferentes processos que incidem e caracterizam seu campo problemático. A fim de compreender melhor o problema, Leff (2010, p. 112) destaca que:

O holismo ao que aspira o pensamento interdisciplinar aparece como uma visão projetada para um objeto teórico inexistente, para um objeto imaginário que levita sobre os campos delimitados de suas aplicações técnicas. O pretendido "holismo" se precipita em seu vazio ontológico antes de conseguir constituir-se num paradigma oniabrangente, de alcançar seu ente totalizador, de ver-se refletido em seu ser totalitário. Talvez o sentido mais profundo do holismo não esteja em sua expressão manifesta, mas em sua queda a esse vazio de significação como signo do limite e impossibilidade de sua vontade totalizadora. A partir de sua impotência emerge sua sedução evocando outro saber, dando novo impulso ao desejo de conhecer.

Para o Biocentrismo, de forma geral, a proteção do meio ambiente realizar-se-ia de forma a beneficiar todos os indivíduos portadores de vida ou toda a natureza, sem estabelecer uma diferenciação entre homens e o meio ambiente. $\mathrm{O}$ valor da vida, em todas as suas dimensões, constitui-se como o principal critério classificatório, ampliando o espectro de seres moralmente consideráveis (NAVES; REIS, 2016).

Com este conceito, o Biocentrismo como teoria desconstrói a endogenia humana e sua posição centralizadora ao inserir todas as formas de vida em posição igualitária, pois nenhuma espécie é superior ou mais importante que a outra, proporcionando uma racionalidade ambiental, uma sustentabilidade em disputa.

\title{
4 A TITULARIDADE DE NOVOS SUJEITOS MORAIS: RESPONSABILIDADE E CUIDADO
}

Desde o inicio, naturalizou-se relacionar-se terra à humanidade. Preservar esse habitat é mais do que um problema de desequilíbrio ambiental. É, antes de tudo, um conflito ético condescendente. Para sair dessa complexidade sistêmica, totalizante, paralisante, e 
autodestrutiva; para reconstruir o mundo nas trilhas da utopia, da possiblidade, da potencialidade do real, das sinergias da natureza, da tecnologia e da cultura; para restabelecer o vínculo entre o ser e o pensar, é necessário uma revolução do pensamento, uma mudança de mentalidade, uma transformação do conhecimento e das práticas educativas, para se construir um novo saber, uma nova racionalidade que orientem a construção de um mundo coerente aos titulares destes direitos (LEFF, 2010).

Nesse sentido, Sampaio (2013) enfatiza que a titularidade pelos direitos fundamentais por excelência é dos indivíduos, mas questiona-se quem pode ser titular de um direito fundamental. Como se sabe, a prevalência destes direitos é herdada de conceitos antropocêntricos em função dos interesses e expectativas dos seres humanos. A fim de compreender melhor o problema, Jonas (2006, p. 229) destaca que:

\begin{abstract}
O futuro da humanidade é o primeiro dever do comportamento coletivo humano na idade da civilização técnica, que se tornou "toda poderosa" no que tange ao seu potencial de destruição. Esse futuro da humanidade inclui, obviamente, o futuro da natureza como sua condição sine qua non. Mas, mesmo independentemente desse fato, este último constitui uma responsabilidade metafísica, na medida em que o homem se tornou perigoso não só para si, mas para toda a biosfera. Mesmo que fosse possível separar as duas coisas - ou seja, mesmo que em um meio ambiente degradado (e em grande parte substituído por artefatos) fosse possível aos nossos descendentes uma vida digna de ser chamada humana, mesmo assim a plenitude da vida produzida durante o longo trabalho criativo da natureza e agora entregue em nossas mãos teria direito de reclamar nossa proteção.
\end{abstract}

Isto implica repensar toda a história do mundo a partir da cisão do ser como ente, pois deve-se levar em consideração as presentes e as futuras gerações. A consagração jurídica de que a Terra é um ser dotado de subjetividade e possui, pois, dignidade e direitos, pode estimular a generalização simbólica da consciência ecológica como um dos meios de apoio do necessário desenvolvimento sustentável (LOVELOCK, 2010)

De fato, o Direito não pode ficar indiferente diante do quadro crítico por que passa o meio ambiente. Então, não pode permanecer alheio às exigências sociais da contemporaneidade. Além de normatizar o que já existe, deve inaugurar realidades novas, de modo que a sociedade se dê conta de uma premência para ela mesma (MURAD; TAVARES, 2016).

Desta feita, visa promover através da busca do ambiente ecologicamente equilibrado a garantia mínima à saúde através da manutenção das condições de existência necessárias, como 
a não poluição de rios e mananciais, o não esgotamento dos recursos naturais e qualidade do solo e o mais importante, diminuir a incidência de CO2 na atmosfera. Desse modo:

\begin{abstract}
A Educação Ambiental deve estar enraizada na realidade social, reorganizando os tempos/espaços e adaptando-os às necessidades da sociedade. Ignacy Sachs, em Caminhos para o Desenvolvimento Sustentável destaca a necessidade de se estabelecerem abordagem interdisciplinares que resultem em possibilidades de utilização dos recursos naturais, com respeito à natureza, afirmando que o uso produtivo destes recursos não precisa resultar em prejuízo para o meio ambiente. $\mathrm{O}$ mesmo enfatiza, também, a necessidade de se entender a biodiversidade para além do conjunto de espécies e genes, mas como um emaranhado de relações constitutivas e resultantes de um complexo processo histórico (CARLI, 2014, p. 42).
\end{abstract}

Portanto, é através da educação Ambiental que teremos a principio a formação consciente e unitária entre governos e sociedade para conter o desequilíbrio ambiental. Pode-se apresentar alternativas de superação destes impasses, á analise problemática através de adequadas políticas de educação para a cidadania estimulando a consciência critica e inovadora da sociedade a respeito do mau uso dos recursos naturais.

\begin{abstract}
Observa-se que a sociedade atual caracteriza-se por atitudes desprovidas de quaisquer indícios de responsabilidade, sendo capaz de causar danos irreparáveis e catastróficos para o ambiente, denotando uma absoluta ausência de comprometimento com o resultado de seus atos e reflexos nas futuras gerações. Tendo por base estas considerações, identifica-se como fundamental a necessidade de que o Poder Público dedique-se, verdadeiramente, às suas atribuições atinentes a Educação Ambiental e ao desenvolvimento sustentável, pois é fato que a insensibilidade das autoridades subtrai dos indivíduos o direito de participar de uma sociedade apoiada no paradigma sistêmico, que reconhece a urgência da efetivação da Educação Ambiental (CARLI, 2014, p. 50).
\end{abstract}

Portanto, é necessário aprofundamentos, pois o desejo de um ambiente limpo e saudável é desejo de todos, mas é imprescindível que o Poder Público importe para si a responsabilidade de transformar o cenário atual. Assim propõe que, pela Teoria de Gaia, a Terra se comporta como ser vivo (LOVELOCK, 2010).

Há uma mudança de paradigma em curso, da visão de mundo cartesiana/mecanicista para uma abordagem holística/sistêmica. Um dos elementos dessa mudança é a Teoria de Gaia, desenvolvida por James Lovelock. Por essa teoria, a Terra é um ente dotado de subjetividade. Trata-se da visão do planeta como um sistema autorregulador constituído pela totalidade de organismos, rochas, oceanos e atmosfera, firmemente acoplados como um sistema em evolução, cujo fim é a regulação de condições favoráveis à vida (MURAD; TAVARES, 2016).

Pode-se afirmar que: 
Todavia, o que se propõe hoje em dia é a definição de formações econômico-sociais como formações sócioprodutivas nas quais se articulam os processos ecológicos, os valores culturais, as mudanças técnicas, o saber tradicional e a organização produtiva, na conformação de novas relações socioambientais e forças ecotecnológicas de produção, orientadas à maximização de um produção sustentável de valores de uso e valores de troca, bem como a articulação destas economias autogestionárias e de autosubsistência, com uma economia global de marcado (LEFF, 2010, p.118).

A concepção do planeta como um organismo vivo permite entendê-lo como um ente que possui autonomia e que deve ser respeitado por possuir dignidade e direitos próprios. Ademais, a metáfora da Terra viva faz lembrar que os homens fazem parte dela e que o contrato com Gaia não tem relação apenas com os direitos humanos, mas inclui também com os deveres humanos. Enquanto os homens não sentirem intuitivamente que a Terra é viva e que fazem parte dela, não poderão reagir para a proteção nem de si mesmos, nem do planeta (LOVELOCK, 2010)

Hans Jonas, em "O Princípio Vida", critica uma ideia de progresso que explora a natureza e alerta para a catástrofe de seguir adiante com essa forma irresponsável de trato com o entorno. Já em "O Princípio Responsabilidade", ele elabora uma ética à altura dos problemas que a civilização tecnológica coloca (JONAS, 2006)

A ética apresentada por Jonas (2006) impõe ao homem do presente velar pela vida e dignidade do homem futuro, o que passa pelo respeito à natureza, pois a vida digna carece do ambiente. Então, a natureza é um bem em si e possui valores, de modo que o trato amável com o entorno se torna imperativo moral. A partir da possibilidade de a civilização tecnológica pôr em perigo o futuro da vida humana digna sobre a Terra, Jonas trata de fundamentar, metafísica e ontologicamente, um imperativo de cuja aplicação derive a preservação desse futuro (BRITO FILHO, 2018).

A compreensão do mundo como 'totalidade' coloca o problema de como integrar os diferentes níveis de materialidade que constituem o ambiente como sistema complexo, e a articulação do conhecimento destas ordens diferenciadas do real, para dar conta destes processos. Nesta construção epistêmica, o pensamento dialético foi seduzido pelo pensamento organicista, pela teoria de sistemas, e pelo estruturalismo genético, de onde a evolução do pensamento e dos conceitos científicos parecem emergir do desenvolvimento complexo da matéria. Do ponto de vista da hermenêutica do ser, a complexidade ambiental questiona a busca da verdade vista como a identidade entre um saber holístico e uma realidade total (LEFF, 2010, p.199). 
A ampliação da responsabilidade torna inviável a assunção acrítica do paradigma antropocêntrico das éticas tradicionais. $\mathrm{O}$ biocentrismo fundamenta $\mathrm{o}$ princípio responsabilidade, que valora a dignidade da vida como tal. Isso é uma exigência moral, não só em razão dos humanos, mas também da biosfera e por seu direito próprio. Logo, Jonas reconhece valor em cada organismo e na natureza em seu conjunto, o que impõe a necessidade de que se respeitem por sua própria dignidade e autonomia (LOVELOCK, 2010).

Percebe-se que a ética proposta por Jonas se adéqua ao que se entende por desenvolvimento sustentável, ou seja, aquele que satisfaça às necessidades da geração atual, sem comprometer a capacidade das gerações futuras de satisfazerem as suas próprias necessidades, com um uso razoável dos recursos da terra e preservando as espécies e os habitats naturais (MURAD; TAVARES, 2016).

\section{CONSIDERAÇÕES FINAIS}

Nos últimos dois séculos o progresso científico legou importantes ganhos para a humanidade. $\mathrm{O}$ homem necessitou adaptar-se na natureza a fim de perpetuar sua sobrevivência, por isso, claramente, a técnica não pode ser criticada em si mesmo, mas, por outro lado, a técnica moderna está associada ao poder.

Assim, a humanidade, vinculada às ideologias de progresso, consumo e tecnologia transformou o meio ambiente. O paradigma antropocêntrico tornou-se tecnocrático. Diante de uma realidade racional e precisamente técnica, o ser humano passou a ocupar outro lugar, o centro, a esfera que determinara o mundo.

Como ser autônomo da realidade, o homem promoveu aspirações próprias e necessidades imediatas. Assim, tudo mais se tornou relativo, o que não servira aos interesses imediatos perdera qualquer importância. Nesta concepção, as fontes de energias, de cunho altamente econômico e controlador, produziram desequilíbrios ecológicos determinando uma alteração significativa no cenário social.

Contudo, percebe-se, cada vez com maior clareza, que esse crescimento econômicoindustrial se contrapõe à natureza, a base material da vida humana. Há na sociedade um conflito de fundo entre a lógica do desenvolvimento econômico e a lógica que governa a biosfera. Tal paradigma leva à crença de que todos os problemas da humanidade serão resolvidos por meio do crescimento econômico, mas não levam em consideração, necessariamente, a desigualdade social, o cuidado com o meio ambiente e com as gerações futuras. 
A economia, a ciência e a técnica buscam uma autossuficiência, sem preocuparem-se com o diálogo com outras áreas e isso leva à crença de que a solução para os problemas criados por elas o seja sem a necessidade de intervenção de outros campos do saber ou paradigmas de vida.

Dentro dessa nova e influente sensibilidade ecológica, mas de forma autônoma, desenvolve-se uma corrente filosófica ética contrária à ética antropocêntrica clássica que foi responsável por uma transformação na postura do homem em relação à natureza. De integrante do meio ambiente, o ser humano passou a colocar-se como parte externa ao meio, a que ele domina e submete.

A concepção do planeta como um organismo vivo permite entendê-lo como um ente que possui autonomia e que deve ser respeitado por possuir dignidade e direitos próprios. Ademais, a metáfora da Terra viva faz lembrar que os homens fazem parte dela e que o contrato com Gaia não tem relação apenas com os direitos humanos, mas inclui também com os deveres humanos.

Enquanto os homens não sentirem intuitivamente que a Terra é viva e que fazem parte dela, não poderão reagir para a proteção nem de si mesmos, nem do planeta. Diante disso, fica evidente que não existem divisões entre a humanidade e o ambiente: um depende do outro para sobreviver e desenvolver-se.

A ampliação da responsabilidade torna inviável a assunção acrítica do paradigma antropocêntrico das éticas tradicionais. Contudo, o Biocentrismo fundamenta-se no princípio da responsabilidade, em que se valora a dignidade da vida como tal. Isso é uma exigência moral, não só em razão dos humanos, mas também em razão da biosfera.

\section{REFERENCIAS}

ALEMAR, Aguinaldo. Direito e ambientalismo: fundamentos para o estudo do Direito ambiental. Belo Horizonte: Arraes, 2013.

AQUINO, Sérgio Ricardo Fernandes de; ZAMBAM, Neuro José. A “Casa Comum”: por uma epistemologia do cuidado e justiça para a América Latina. Revista Veredas do Direito, Belo Horizonte, v. 14, n. 29, p. 101-123, maio/ago. 2017. Disponível em: <http://www.domhelder.edu.br/revista/index.php/veredas/article/view/999>. Acesso em: 06 jun. 2018.

BRASIL. Constituição (1988). Constituição da República Federativa do Brasil. Brasília: Senado Federal, Centro Gráfico, 1988. 
BRASIL. Lei n. 6.938, de 31 de Agosto de 1981. Política Nacional do Meio Ambiente. Disponível em: <http://www.planalto.gov.br/ccivil_03/leis/L6938.htm>. Acesso em: 23 jun. 2017.

BRITO FILHO, José Claudio Monteiro de. Direito Humanos. 2. ed. São Paulo: L.Tr, 2018.

BOFF, Leonardo. Ética da vida: a nova centralidade. Rio de Janeiro: Record, 2009.

BOFF, Leonardo. Saber cuidar: Ética do humano - compaixão pela terra. 19. ed. Petrópolis: Vozes, 2013.

BOFF, Leonardo. Sustentabilidade: o que é: o que não é. Petrópolis, (RJ): Vozes, 2012.

CARLI, Ana Alice de (Org.); MARTINS, Saadia Borba (Org.). Educação Ambiental: premissa inafastável ao desenvolvimento econômico sustentável. Rio de Janeiro: Lumen Juris, 2014.

FABRIZ, Daury Cesar. Bioética e direitos fundamentais: a bioconstituição como paradigma do biodireito. Belo Horizonte: Mandamentos, 2003.

FRANCISCO. Laudato si: sobre o cuidado da casa comum. São Paulo:

Paulus Loyola, 2015.

GRANZIERA, Maria Luiza Machado. Direito ambiental. 3. ed. São Paulo: Atlas, 2014.

JONAS, Hans. O princípio responsabilidade: ensaio de uma ética para a civilização tecnológica. Rio de Janeiro: Contraponto, 2006.

JONAS, Hans. O princípio vida: fundamentos para uma biologia filosófica. Petrópolis: Vozes, 2004.

LEFF, Henrique. Epistemologia ambiental. São Paulo: Cortez, 2010.

LOVELOCK, James. 1919-Gaia: Alerta Final. Tradução Vera de Paula Assis e Jesus de Paula Assis. Rio de Janeiro: Intrínseca, 2010.

MILARÉ, Èdis. Direito do ambiente: a gestão ambiental em foco: doutrina, jurisprudência, glossário. 9. ed. São Paulo: Revista dos Tribunais, 2014.

MURAD, Afonso (Coord.); TAVARES, Sinivaldo Silva (Coord.). Cuidar da casa comum: chaves de leitura teológicas e pastorais da Laudato Si. São Paulo: Paulinas, 2016.

NAVES, Bruno Torquato de Oliveira (Coord.); FERNANDES, Fabíola Ramos (Coord.); NASCMENTO, Simone Murta Cardoso do (Coord.). Repercussões éticas e jurídicas da genética: apontamentos sobre os impactos na saúde e no meio ambiente. Belo Horizonte: Arraes, 2016. 
NASCIMENTO, Simone Murta Cardoso do. Meio ambiente e saúde: desdobramentos éticos e jurídicos da inter-relação entre condições ambientais e genética humana. Rio de Janeiro: Lumen Juris, 2016.

NAVES, Bruno Torquato de Oliveira; REIS, Émilien Vilas Boas. Bioética ambiental: premissas para o diálogo entre a Ética, a Bioética, o Biodireito e o Direito Ambiental. Rio de Janeiro: Lumen Juris, 2016.

REIS, Émilien Vilas Boas; BIZAWU, Kiwonghi. A encíclica Laudato Si à luz do direito internacional do meio ambiente. Revista Veredas do Direito, Belo Horizonte, v. 12, n. 23, Jan/jun. de 2015, p. 29-65. Disponível em: <http://www.domhelder.edu.br/revista/index.php/veredas/article/ view/598/439>. Acesso em: 12 jun. 2018.

REIS, Émilien Vilas Boas; NAVES, Bruno Torquato Oliveira.; RIBEIRO, Luiz Gustavo Gonçalves. Um Posicionamento Jurídico-Filosófico Contra A Metafísica Dos "Ismos": Uma Análise Sobre Os Animais. Veredas do Direito, Belo Horizonte, v. 15, n. 31, p. 67-94, jan./abr. $2018 . \quad$ Disponível em: <http:// www.domhelder.edu.br/revista/index.php/veredas/article/view/1265>. Acesso em: 30 jun. 2018.

RIBEIRO, Gustavo Pereira Leite (Coord.); TEIXEIRA, Ana Carolina Brochado (Coord.). Bioética e direitos da pessoa humana. Belo Horizonte: Del Rey, 2012.

SÁ, Maria de Fátima Freire de; NAVES, Bruno Torquato de Oliveira. Manual de biodireito. Belo Horizonte: Del Rey, 2009.

SALLES, Alvaro Angelo (Org.). Bioética: reflexões interdisciplinares. Belo Horizonte: Mazza, 2009.

SAMPAIO, José Adércio Leite. Teoria da constituição e dos direitos fundamentais. Belo Horizonte: Del Rey, 2013. 